\title{
Neurodevelopment of small-for-gestational age infants: behavioral aspects in first year
}

\author{
Neurodesenvolvimento de lactentes pequenos para a idade gestacional, aspectos \\ comportamentais no $1^{\circ}$ ano
}

Bernadete Mello ${ }^{1}$, Heloisa Gagliardo ${ }^{1}$, Vanda Gonçalves ${ }^{2}$

\begin{abstract}
The purpose of this study was to compare the behavior of full-term small-for-gestational age (SGA) with full-term appropriate-for gestational age (AGA) infants in the first year of life. We prospectively evaluated 68 infants in the $2^{\text {nd }}$ month, 67 in the $6^{\text {th }}$ month and 69 in the $12^{\text {th }}$ month. The Bayley Scales of Infant Development-II were used, with emphasis on the Behavior Rating Scale (BRS). The groups were similar concerning the item "interest in test materials and stimuli"; there was a trend toward differences in the items "negative affect", "hypersensitivity to test materials" and "adaptation to change in test materials". The mean of Raw Score was significantly lower for the SGA group in the items "predominant state", "liability of state of arousal", "positive affect", "soothability when upset", "energy", "exploration of objects and surroundings", "orientation toward examiner". A lower BRS score was associated with the SGA group in the $2^{\text {nd }}$ month.
\end{abstract}

Keywords: child behavior, child development, fetal growth retardation.

\section{RESUMO}

O objetivo deste estudo foi comparar o comportamento de lactentes nascidos a termo, pequenos para a idade gestacional (PIG) e lactentes nascidos com peso adequado para a idade gestacional (AIG). Foram avaliados prospectivamente 68 lactentes no $2^{\circ}$ mês, 67 no $6^{\circ}$ mês e 69 no $12^{\circ}$ mês. Para avaliação foi utilizado as Escalas Bayley do Desenvolvimento Infantil-II com ênfase na escala de Avaliação do Comportamento (BRS). Os grupos foram semelhantes quanto ao item: interesse nos materiais do teste e estímulos; observou-se uma tendência à diferença nos itens afeto negativo, hipersensibilidade aos materiais/estímulos do teste e adaptação às mudanças dos materiais. A média do Raw Score foi significativamente mais baixa no grupo de lactentes PIG nos itens: estado predominante, labilidade do estado de alerta, afeto positivo, exploração de objetos/ambiente e interação com o examinador. Os resultados de scores na BRS foram menores no $2^{\circ}$ mês, no grupo de lactentes PIG.

Palavras-chave: comportamento infantil, desenvolvimento infantil, retardo do crescimento fetal.

The term SGA is a statistical concept based on the distribution of birth weights by gestational length. Infants with intrauterine growth retardation syndrome or SGA infants are identified as those with a birth weight below the $10^{\text {th }}$ percentile of intrauterine growth standards. The $10^{\text {th }}$ percentile of the widely used Lubchenco curves agrees quite well with the corresponding curves of other authors ${ }^{1}$. It describes a neonate whose birth weight or birth crown-heel length is at least 2 standard deviations below the mean for the infant's gestational age, based on data derived from a reference population. SGA also has been defined in some publications as birth weight or length below the $10^{\text {th }}, 5^{\text {th }}$, or $3^{\text {rd }}$ percentile for gestational age $\mathrm{e}^{2,3}$.
The development of SGA newborns has continually been the target of research because it is considered a model of malnutrition at precocious age. Since the 1960s and 70s the attention of researchers has been caught by the fact that half of all children in the world suffer from a certain degree of malnutrition, a condition that could permanently limit their intellectual capacity in a technologically advanced world ${ }^{4}$.

Infants born SGA are at increased risk for a range of adverse physical and developmental outcomes. The long-term effects of fetal growth retardation on intellectual and educational outcome showed association with subtle delays in development, as well as mild behavior and

${ }^{1}$ Departamento de Desenvolvimento Humano e Reabilitação, Universidade Estadual de Campinas, Campinas SP, Brazil;

${ }^{2}$ Departamento de Neurologia, Universidade Estadual de Campinas, Campinas SP, Brazil.

Correspondence: Bernadete Mello; Departamento de Desenvolvimento Humano e Reabilitação, Universidade Estadual de Campinas; Rua Tessália Vieira de Camargo, 126; 13083-887 Campinas SP, Brasil; E-mail: berna@fcm.unicamp.br

Conflict of interest: There is no conflict of interest to declare.

Received 16 September 2013; Received in final form 25 April 2014; Accepted 15 May 2014. 
learning problems or to deficiencies in their ability to elicit caregiver responsiveness ${ }^{5,6,7,8}$.

Many studies of neurodevelopmental outcomes in SGA infants have been conducted in industrialized countries. More information is needed from developing countries, where SGA is a much more severe public health problem? Taking into account the number of SGA children at risk, few studies have been carried out in developing countries. The only well-documented reports we are aware of in Brazil showed that SGA full-term infants had poorer development than AGA infantsor showed abnormal neurological examination results ${ }^{5,10,11,12,13,14,15,16}$.

The present study was conducted with the aim of assessing and comparing the neurodevelopment of two cohorts of full-term Brazilian infants, a SGA group compared with an AGA control group in the first year of life, with emphasis on the behavioral score. The specific hypothesis tested was that the SGA infants would demonstrate different behavioral development in the first year of life.

\section{METHOD}

The research design was a prospective study of two cohorts of full-term infants, one of them a SGA group compared with an appropriate for gestational age (AGA) control group in the period from September 2000 to August 2001. All of them were neonates delivered at the Neonatology Service of the Center for Integral Attention to Women's Health (CAISM) of the State University of Campinas (UNICAMP), Sao Paulo, Brazil. For each SGA neonate that was chosen, the next two AGA neonates were selected. Approval was obtained from the Research Ethics Committee of the School of Medical Sciences, UNICAMP, and the mothers also gave their informed consent for their children's participation in the study.

They were selected according to the following criteria: subjects living in the metropolitan area of Campinas; neonates considered in good health to go home within 2 days after birth; gestational age categorized as full-term (37-41 weeks) by the Capurro postnatal method ${ }^{17}$; expected birth weight for gestational age determined by the Battaglia and Lubchenco ${ }^{1}$ method; birth weight below the $10^{\text {th }}$ percentile on the intrauterine growth curve for the SGA group, whereas AGA infant birthweights fell between the $10^{\text {th }}$ and the $90^{\text {th }}$ percentiles.

Infants were excluded from this study if there was evidence of genetic syndromes, multiple congenital malformations and verified congenital infections (syphilis, toxoplasmosis, rubella, cytomegalovirus and herpes).

Collected and examined perinatal variables were gender, gestational age, birth weight, birth weight centile. All children were scheduled for development evaluation. Two professionals who were unaware of the neonate's group classification assessed the infants once a month, from 7 days before to 7 days after their birth day, in the presence of their mothers, throughout their first year of life. In this study, we report data collected at the $2^{\text {nd }}, 6^{\text {th }}$ and $12^{\text {th }}$ months.

The Bayley Scales of Infant Development-II (BSID-II) ${ }^{18}$ were used. The infant's score for each item was registered in the Mental, Motor and Behavior Rating Scales (BRS) Record Forms. Both the index scores (IS) and the raw scores (RS) were considered in the analysis, with emphasis on the BRS.

In the Mental and Motor scales the mean IS was 100 with a standard deviation (SD) of 15. A well-defined terminology system classified the IS as: accelerated performance ( $\geq 115$ ); within normal limits (85-114); mildly delayed performance (70-84); and significantly delayed performance $(\leq 69)^{18}$.

The BRS describes the child's state, orientation, motivation, and may partially explain variations in individual performance on the Mental and Motor Scales. For the youngest children (1-5 months), the BRS assesses Attention/ Arousal and Motor Quality Factors. For older children (6-42 months) the BRS assesses Orientation/Engagement, Emotional Regulation, and Motor Quality Factors.

The Attention/Arousal Factors item includes an assessment of the infant's condition, affectivity, energy, interest, exploration, and responsiveness to the examiner. The Motor Quality Factor refers to the quality of the infant's movements, including tone and control. Orientation/ Engagement includes items of the Attention/Arousal Factor, along with additional items that assess aspects of the infant's behavior toward the materials. Emotional Regulation is an assessment of the infant's range of affective and emotional response to both success and failure during evaluation.

The BRS considers the RS converted into percentiles for each factor within each age group. A total RS can also be converted into a percentile by age group to provide an overall assessment of the infant's behavior. Percentile ranks from 1-10 were non optimal, from 11-25 were questionable, and $>25$ were within normal limits.

\section{Statistical methods}

The data were registered in an SPSS/PC database (Statistical Package for Social Sciences for Personal Computer 11.0). Statistical analysis was carried out using the Statistical Analysis System for Windows, version 6.12 (SAS Institute Inc, 1989-1996). Values are expressed as mean $\pm \mathrm{SD}$ or median, as appropriate. To determine the relationship between continuous variables (IS of the Mental / Motor Scales and RS of the BRS) the Mann-Whitney test was used. Chi-squared or Fisher exact test were used to 
compare proportions between groups. The probability level for rejection of the null hypothesis was $\mathrm{p} \leq 0.05$.

\section{RESULTS}

The sample for the prospective study of two cohorts with cross-sectional data analyses consisted of 68 infants (25 SGA and $43 \mathrm{AGA}$ ) in the $2^{\text {nd }}$ month, 67 infants (25 SGA and 42 AGA) in the $6^{\text {th }}$ month and 69 infants (22 SGA and 47 AGA) in the $12^{\text {th }}$ month.

Gestational age was similar in both groups $(\mathrm{p}=0.808)$. Comparison of the birth weights showed statistically significant differences $(\mathrm{p}<0.001)$, with lower mean birth weight for the SGA group, indicating that the method for subject classification in each group was correct.

Table 1 shows the relationship between chronological age, IS in the Mental and Motor Scales and RS in the BRS in the $2^{\text {nd }}, 6^{\text {th }}$ and $12^{\text {th }}$ month. The groups were similar in the mean IS of the Mental Scale. There was significant difference in the Motor Scale in the $2^{\text {nd }}$ and $12^{\text {th }}$ months, showing a trend toward differences between groups in the $6^{\text {th }}$ month, with lower mean IS in the SGA group. In the BRS, the mean RS was significantly lower in the SGA group in the $2^{\text {nd }}$ month.

The BRS assessed the Attention/Arousal and Motor Quality Factors. The groups showed similar Attention/ Arousal Factor performances in the $6^{\text {th }}$ and $12^{\text {th }}$ month. There were significant differences in the $2^{\text {nd }}$ month, with higher frequency of the SGA group classified as questionable/non-optimal and the AGA group classified as within normal limits (Table 2). In the Motor Quality Factor both groups showed similar classifications in the $2^{\text {nd }}, 6^{\text {th }}$ and $12^{\text {th }}$ months.

The Attention/Arousal Factor assessed 11 items. The groups were similar in the item interest in test materials and stimuli; there was a trend to differences in the items "negative affect", "hypersensitivity to test materials" and "adaptation to change in test materials". The mean RS was significantly lower for the SGA group in the items: "predominant state", "liability of state of arousal", "positive affect", "soothability when upset", "energy", "exploration of objects and surroundings" and "orientation toward examiner" (Table 3).

In the Motor Quality Factor, both groups showed similar classification as "questionable/non optimal". Considering the mean RS for the items of the Motor Quality Factor (Table 4), the differences were significant between the groups, with the SGA group performing poorly in grossmotor and control movements and significantly higher mean RS for hypotonicity in the SGA group.

\section{DISCUSSION}

In this study, the groups were similar concerning the mean IS in the Mental Scale; it showed significantly lower IS in the $2^{\text {nd }}$ month in the Motor Scale and RS in the BRS in SGA infants. These seemed transient minor alterations.

Table 1. Comparison of the scores in the Mental, Motor and Behavior Rating Scales of the SGA and AGA groups in the $1^{\text {st }}$ year.

\begin{tabular}{|c|c|c|c|c|c|c|c|}
\hline Chronological Age (month) & Group & Mean & SD & Min & Median & Max & $\mathrm{p}^{\mathrm{a}}$ \\
\hline \multirow[t]{2}{*}{$2^{\text {nd }}$} & SGA & 86.44 & 9.87 & 62.00 & 90.00 & 101.00 & 0.097 \\
\hline & AGA & 91.37 & 9.75 & 62.00 & 92.00 & 111.00 & \\
\hline \multirow[t]{2}{*}{$6^{\text {th }}$} & SGA & 90.16 & 7.07 & 74.00 & 90.00 & 100.00 & 0.103 \\
\hline & AGA & 93.19 & 5.28 & 80.00 & 94.00 & 102.00 & \\
\hline \multirow[t]{2}{*}{$12^{\text {th }}$} & SGA & 97.91 & 13.08 & 70.00 & 102.00 & 120.00 & 0.669 \\
\hline & AGA & 97.36 & 9.24 & 74.00 & 96.00 & 113.00 & \\
\hline \multicolumn{8}{|c|}{ Motor Scale } \\
\hline \multirow[t]{2}{*}{$2^{\text {nd }}$} & SGA & 89.76 & 6.12 & 78.00 & 90.00 & 108.00 & $0.008 *$ \\
\hline & AGA & 93.49 & 7.58 & 72.00 & 93.00 & 114.00 & \\
\hline \multirow[t]{2}{*}{$6^{\text {th }}$} & SGA & 88.54 & 8.22 & 73.00 & 85.00 & 104.00 & 0.057 \\
\hline & AGA & 93.31 & 9.11 & 76.00 & 92.50 & 114.00 & \\
\hline \multirow[t]{2}{*}{$12^{\text {th }}$} & SGA & 91.14 & 15.34 & 50.00 & 93.00 & 121.00 & $0.047 *$ \\
\hline & AGA & 98.79 & 13.24 & 69.00 & 101.00 & 121.00 & \\
\hline \multicolumn{8}{|c|}{ Behavior Rating Scale } \\
\hline \multirow[t]{2}{*}{$2^{\text {nd }}$} & SGA & 72.56 & 9.50 & 53.00 & 76.00 & 84.00 & $0.001 *$ \\
\hline & AGA & 78.53 & 11.59 & 16.00 & 81.00 & 90.00 & \\
\hline \multirow[t]{3}{*}{$6^{\text {th }}$} & SGA & 125.04 & 17.21 & 59.00 & 130.00 & 139.00 & 0.103 \\
\hline & AGA & 130.69 & 10.14 & 93.00 & 135.00 & 140.00 & \\
\hline & SGA & 131.18 & 8.56 & 106.00 & 134.00 & 140.00 & \\
\hline $12^{\text {th }}$ & AGA & 132.28 & 7.22 & 107.00 & 134.00 & 140.00 & 0.679 \\
\hline
\end{tabular}

SGA: small-for-gestational age; AGA: appropriate for gestational age; SD: standard deviation; Min: minimum; Max: maximum; ${ }^{a}$ Mann-Whitney test; * significant differences. 
Table 2. Classification of Attention/Arousal and Motor Quality Factors of the SGA and AGA groups in the $2^{\text {nd }}$ month.

\begin{tabular}{lccc}
\hline $\begin{array}{l}\text { Group } \\
f(\%)\end{array}$ & $\begin{array}{c}\text { Questionable/non- optimal } \\
f(\%)\end{array}$ & $\begin{array}{c}\text { Within normal limits } \\
f(\%)\end{array}$ \\
\hline SGA & $8(32.00)$ & $17(68.00)$ \\
AGA & $6(13.96)$ & $37(86.05)$ & $0.005^{\star}$ \\
\hline \multicolumn{3}{c}{ Motor Quality Factor } \\
\hline SGA & $6(24.00)$ & $19(76.00)$ \\
AGA & $4(9.30)$ & $39(90.70)$ \\
\hline
\end{tabular}

SGA: small-for-gestational age; AGA: appropriate for gestational age; ${ }^{b}$ Fisher test; *statistical significant difference.

We conjectured that this may indicate that, in the AGA group so-called major transformation of neural functions that take place at about the end of the post-term $2^{\text {nd }}$ month ocurred $^{19}$. Many neural functions change into a more adaptive condition than during the first months after a term birth $^{20}$. Presumably in the SGA group major transformations of neural functions will occur further along. Thus, term SGA newborns with no signs of placental insufficiency had poorer neurobehavioral competency, which suggests delayed neurological maturation.

The results illustrate that chronic malnutrition may also impair maturation of the central nervous system in humans. Whether such difference found in this study at the $2^{\text {nd }}$ month has any clinical significance is uncertain, as is the extent to which it may predict developmental or learning problems at a later stage.

The mean IS in the Mental Scale was lower for the SGA group, but the differences were not statistically significant. The same results were observed, examining the cognitive development of full-term SGA and AGA groups ${ }^{21}$. The AGA infants performed better on the Bayley Mental Scale than the SGA infants at the $12^{\text {th }}$ and $18^{\text {th }}$ months of age, but the differences were not statistically significant. The same results were also observed, which reported that nine SGA infants had a lower Bayley score than 10 control infants ${ }^{22}$.

We observed significant differences between the groups in the BRS, in the Attention/Arousal Factor during the $2^{\text {nd }}$ month, which showed a higher frequency of the SGA group classified as questionable/non-optimal and the AGA group classified as within normal limits. The SGA group performed poorly in some items of the Attention/Arousal Factor: "predominant state", "liability of state of arousal", "positive affect", "soothability when upset", "energy", "exploration of objects and surroundings" and "orientation toward examiner”.

Some of these items refer to the interactive processes, to the infant's capability to respond to social stimuli, especially during the alert state. To evaluate this dimension the items: "predominant state", "liability of state of arousal", "positive affect", "exploration of objects and surroundings" and "orientation toward examiner" were selected. The SGA group showed significantly lower mean RS. The differences in interactive behavior between the groups were even more pronounced, as indicated by the over-all rating of attractiveness and need for and use of stimulation. Although the child comes to an alert state, its responsiveness is poor.

Table 3. Comparison of items of Attention/Arousal Factor of the SGA and AGA groups in the $2^{\text {nd }}$ month.

\begin{tabular}{|c|c|c|c|c|c|c|c|}
\hline Items & Groups & Mean & SD & Min & Median & Max & $p^{a}$ \\
\hline \multirow[t]{2}{*}{ Predominant state } & SGA & 3.84 & 0.85 & 2.00 & 4.00 & 5.00 & $0.016 *$ \\
\hline & AGA & 4.33 & 0.84 & 2.00 & 5.00 & 5.00 & \\
\hline \multirow[t]{2}{*}{ Liability of state of arousal } & SGA & 3.84 & 0.90 & 2.00 & 4.00 & 5.00 & $0.030 *$ \\
\hline & AGA & 4.30 & 0.83 & 2.00 & 4.00 & 5.00 & \\
\hline \multirow[t]{2}{*}{ Positive affect } & SGA & 2.76 & 1.33 & 1.00 & 3.00 & 5.00 & $0.016^{*}$ \\
\hline & AGA & 3.60 & 1.31 & 1.00 & 4.00 & 5.00 & \\
\hline \multirow[t]{2}{*}{ Negative affect } & SGA & 3.60 & 1.12 & 1.00 & 4.00 & 5.00 & 0.051 \\
\hline & AGA & 4.09 & 1.04 & 1.00 & 4.00 & 5.00 & \\
\hline \multirow[t]{2}{*}{ Soothability when upset } & SGA & 3.80 & 1.26 & 1.00 & 4.00 & 5.00 & $0.009 *$ \\
\hline & AGA & 4.49 & 0.96 & 1.00 & 5.00 & 5.00 & \\
\hline \multirow[t]{2}{*}{ Energy } & SGA & 3.68 & 0.90 & 2.00 & 4.00 & 5.00 & $0.001 *$ \\
\hline & AGA & 4.40 & 0.82 & 1.00 & 5.00 & 5.00 & \\
\hline \multirow[t]{2}{*}{ Interest in test materials and stimuli } & SGA & 3.20 & 1.22 & 1.00 & 3.00 & 5.00 & 0.117 \\
\hline & AGA & 3.67 & 1.13 & 1.00 & 4.00 & 5.00 & \\
\hline \multirow{2}{*}{ Exploration of objects and/or surroundings } & SGA & 3.88 & 1.09 & 1.00 & 4.00 & 5.00 & $0.004^{*}$ \\
\hline & AGA & 4.53 & 0.83 & 1.00 & 5.00 & 5.00 & \\
\hline \multirow[t]{2}{*}{ Orientation to examiner } & SGA & 4.04 & 0.93 & 2.00 & 4.00 & 5.00 & $0.002 *$ \\
\hline & AGA & 4.63 & 0.76 & 2.00 & 5.00 & 5.00 & \\
\hline
\end{tabular}

AGA: appropriate for gestational age; SGA: small-for-gestational age; SD: standard deviation; Min: minimum; Max: maximum; ${ }^{a}$ Mann-Whitney test; *significant differences. 
Table 4. Comparison of items of Motor Quality Factor of the SGA and AGA groups in the $2^{\text {nd }}$ month.

\begin{tabular}{|c|c|c|c|c|c|c|c|}
\hline Items & Groups & Mean & SD & Min & Median & Max & $\mathrm{p}^{\mathrm{a}}$ \\
\hline \multirow[t]{2}{*}{ Gross-Motor Movement } & SGA & 3.76 & 0.7 & 3.00 & 4.00 & 5.00 & $0.005 *$ \\
\hline & AGA & 4.27 & $\begin{array}{c}2 \\
0.7 \\
1\end{array}$ & 2.00 & 4.00 & 5.00 & \\
\hline \multirow[t]{2}{*}{ Control Movement } & SGA & 3.60 & $\begin{array}{c}0.7 \\
1\end{array}$ & 2.00 & 4.00 & 5.00 & $0.004^{\star}$ \\
\hline & AGA & 4.12 & $\begin{array}{c}0.7 \\
1\end{array}$ & 2.00 & 4.00 & 5.00 & \\
\hline \multirow[t]{2}{*}{ Hypotonicity } & SGA & 4.92 & $\begin{array}{c}0.2 \\
8\end{array}$ & 4.00 & 5.00 & 5.00 & $0.008^{*}$ \\
\hline & AGA & 4.60 & $\begin{array}{c}0.5 \\
4\end{array}$ & 3.00 & 5.00 & 5.00 & \\
\hline \multirow[t]{2}{*}{ Hypertonicity } & SGA & 3.96 & $\begin{array}{c}0.7 \\
3\end{array}$ & 2.00 & 4.00 & 5.00 & 0.355 \\
\hline & AGA & 4.14 & $\begin{array}{c}0.6 \\
1\end{array}$ & 3.00 & 4.00 & 5.00 & \\
\hline \multirow[t]{2}{*}{ Tremulousness } & SGA & 4.44 & $\begin{array}{c}1.1 \\
6\end{array}$ & 1.00 & 5.00 & 5.00 & 0.129 \\
\hline & AGA & 4.86 & $\begin{array}{c}0.3 \\
5\end{array}$ & 4.00 & 5.00 & 5.00 & \\
\hline \multirow[t]{2}{*}{ Frenetic Movement } & SGA & 4.72 & $\begin{array}{c}0.7 \\
4\end{array}$ & 2.00 & 5.00 & 5.00 & 0.85 \\
\hline & AGA & 4.76 & $\begin{array}{c}0.6 \\
6\end{array}$ & 2.00 & 5.00 & 5.00 & \\
\hline
\end{tabular}

AGA: appropriate for gestational age; SGA: small-for-gestational age; SD: standard deviation; Min: minimum; Max: maximum; aMann-Whitney test; *significant differences.

SGA infants have been described as being more irritable, less approachable, more avoidant to stimulation, and having impaired patterns of interaction compared to appropriately grown peers. Thus, irritable infants may not receive the enriching stimulation that they need to enhance their development $t^{5,22,23}$.

SGA newborns were found to behave substantially differently from their AGA peers on interactive processes. Although they come to an alert state, their responsiveness is poor. There was significant difference in interactive behavior including poor response to stimulus; they interacted more poorly with their environment, with the examiner or inanimate objects and when they were manipulated they demonstrated stress and exhaustion, feeling uncomfortable $\mathrm{e}^{23,24}$.

A pattern of predictive correlations was obtained between neonatal reactivity and later temperament development at 24-month for AGA/SGA twin pairs ${ }^{25}$. Infant temperament ratings were made of emotional tone, activity, attentiveness, and social orientation toward staff during age-appropriate activities in the laboratory. For AGA twins, a pattern of predictive correlations was obtained between neonatal reactivity and temperament at each age. A similar predictive pattern was not observed for the SGA twins. Group differences in maturation rates related to stress associated with intrauterine growth retardation influenced the significance of the neonatal variables for later temperament development.
Concerning the organization of behavioral states in the first months of the SGA infants, they were of special interest because they provided an index of the organization of the multiple neurological measurements. The indexes of organization of behavioral states were related to malfunction on the subsequent development ${ }^{12,22,26}$.

We observed that the groups were similar in the Motor Quality Factor in the $2^{\text {nd }}$ month when classified either as within normal limits or as questionable/non-optimal. However, there were significant differences in the mean RS that was significantly lower in the gross-motor and control movement items and significantly higher in hypotonicity for the SGA group.

Abnormal postnatal movement patterns have also been reported in the literature ${ }^{27}$. Applying the principle of exclusion the hypothesis remains that the abnormal motor behavior of the growth retarded fetus is due to impairment of neural development, caused by chronic nutritional deprivation.

Most likely the quality of movement expresses alteration of central nervous system development in full-term SGA infants ${ }^{27,28}$. Many infants with growth retardation have transiently abnormal general movements, indicating the importance of obtaining multiple observations. It has been suggested that abnormalities at a young age are related to lesions of neural subsystems whose role in motor control ceases after 2 to 3 months. These abnormalities may disappear if the new, post-transformation of neural functions is not impaired ${ }^{27,29}$. 
In SGA newborns it was observed that they markedly differed in motor behavior. They tended to showed hyperexcitability, an increased frequency of arm movements and difference for fine motor skills between the groups ${ }^{23}$.

Neonates SGA were found to behave substantially differently from their AGA peers on motor behavior. The typical underweight newborn tends to have poor muscular tone, very low activity levels, poor defensive reaction and jerky or cogwheel-like movement of the limbs with restricted arcs. It is floppy in the pull-to-sit movement and does not show good modulation when being passively moved ${ }^{21}$.

Based on patterns of neuronal development, an injury during the first half of pregnancy may lead to defects in the production and migration of neurons of the cerebral cortex, whereas during the last trimester an injury could compromise neuronal growth and differentiation. Growth retardation may affect infant behavior in several ways. Compromised development of limbic structures could influence the processing of basic emotions, while alterations in cortical areas in general and prefrontal cortex in particular are likely to affect attention and self-regulatory process.
Compared to infants who have had an uneventful prenatal course, infants who have experienced fetal growth retardation may show differences in the quantity or quality of emotion and their associated motivational dispositions.

We concluded that in the $2^{\text {nd }}$ month the SGA infants of this sample showed significantly lower scores in the Motor Scale and in the BRS.

In the BRS, we observed that in the Attention/Arousal Factor the groups were similar regarding the item "interest in test materials and stimuli"; there was a trend to differences in the items "negative affect", "hypersensitivity to test materials" and "adaptation to change in test materials". The mean RS was significantly lower for the SGA group in the items: "predominant state", "liability of state of arousal", "positive affect", "soothability when upset", "energy", "exploration of objects and surroundings" and "orientation toward examiner".

Considering the mean RS for the items of the Motor Quality Factor, the SGA group performed poorly in grossmotor and control movements and showed significantly higher mean RS for hypotonicity in the SGA group.

\section{References}

1. Lubchenco LO, Hansman C, Dressler M, Boyd E. Intrauterine growth as estimated from liveborn birth-weight data at 24 to 42 weeks of gestation. Pediatrics 1963;11:793-800

2. Lee PA, Chernausek SD, Hokken-Koelega AC, et al. International small for gestational age advisory board consensus. Development Conference Statement: Management of short children born small for gestational age. Pediatrics 2003;111:1253-1261.

3. Watt J. Interaction and development in the first year II. The effects of intrauterine growth retardation. Early Hum Dev 1986;13:211-223.

4. Levitsky DA, Strupp BJ. Malnutrition and brain: changing concepts, changing concerns. J Nutr 1995;125:2212-2220.

5. Black MM, Sazawal S, Black,RE, Khosla S, Kumar J, Menon V. Cognitive and motor development among small-for-gestational-age infants: impact of zinc supplementation, birth weighr, and caregiver practices. Pediatrics 2004;113:1297-1305.

6. Strauss R. S. Adult functional outcome of those born small for gestational age. JAMA 2000;283:625-632.

7. Paz I, Laor A, Gale R, Harlap S, Stevenson DK, Seidman DS. Term infants with fetal growth restriction are not increased risk for low intelligence scores at age 17 years. J Pediatr 2001;138:87-91.

8. Tolsa CB, Zimine S, Warfield SK, et al. Early alteration of structural and functional brain development in premature infants born with intrauterine growth restriction. Pediatric Res 2004;56:132-138.

9. Goldenberg RL, Hoffman HJ, Cliver SP. Neurodevelopment outcome of small-for-gestational-age infants. Eur J Clin Nutr 1998;8:52-54.

10. Morris SS, Grantham-McGregor SM, Lira PIC, Assunção AM, Ashworth A. Effect of breastfeeding and morbidity on the development of low birthweight term babies in Brazil. Acta Paediatr 1999;88:1101.

11. Eickman S.H, Lima M.C. Desenvolvimento mental e motor aos 24 meses de crianças nascidas a termo com baixo peso. Arq Neuropsiquiatr 2001;60:748-654.
12. Mello BBA, Gonçalves VMG, Souza AP. Behavior full term infants small for gestational age in the first three months of life. Arq Neuropsiquiatr 2004;62:1046-1051.

13. Gagliardo HGRG, Gonçalves VMG, Lima MCMP, Françozo MFC, Netto A A. Visual function and fine-motor control in small-for-gestational age infants. Arq Neuropsiquiatr 2004;62:1-13.

14. Goto MM, Gonçalves VM, Netto AA, Morcilo AM, Moura-Ribeiro MV. Neurodevelopment of full-term small-for-gestational age infants in the second month of life. Arq Neuropsiquiatr 2005;63:75-82.

15. Gherpelli JLD, Ferreira H, Costa PFH. Neurological follow-up of smallfor-gestational age newborn infants. Arq Neuropsiquiatr 1993;51:50.

16. Oliveira KF. O exame neurológico de recém-nascidos pequenos para a idade gestacional, comparado aos recém-nascidos adequados. Neurobiol 1997;60:75-90.

17. Capurro H, Konichezky S, Fonseca D, Caldeyro-Barcia R. A simplified method for diagnosis of gestational age in the newborn infant. J Pediatr 1978;93:120-122.

18. Bayley N. Bayley Scales on Infant development. $2^{\text {nd }}$ ed. San Antonio: The Psychological Corporation, 1993:374.

19. Prechtl HFR. Continuity of neural functions from prenatal to postnatal life. Clin Dev Med n 94. London: Spastics International Medical Publications; 1984.

20. Prechtl HFR. New perspectives in early human development. Eur L Obstet Gyneco Reprod Biol 1986;21:347-355.

21. Halpern LF, Garcia Coll CT, Meyer EC, Bendersky K. The contributions of temperament and maternal responsiveness to the mental development of small-for-gestational-age and appropriate-forgestational-age infants. J App Dev Psychol 2001;22:199.

22. Watt J, Strongman KT. Mother-infant interaction at 2 and 3 months in preterm, small-for-gestational-age, and full-term infants; their relationship with cognitive development at 4 months. Early Hum Dev 1985;11:231-246. 
23. Arias AV, Gonçalves VMG, Campos D, Santos DCC, Goto MF, Zanelli TM. Small-for-gestational-age newborn infant: repercussion on fine motor skills. Rev Paul Pediatr 2011;29:21-28.

24. Abrol P, Kappor R, Gathwala G, Tiwari AD. Neonatal behavior in full term small for date. Idian Pediatrics 1994;31:785-789.

25. Riese ML. Predicting infant temperament from neonatal reactivity for AGA/SGA twin pars. Twin Res 1998;1:65-70.

26. Stern E, Parmelee, AN, Akiyama, Y, Achultz, MZ, Wenner WH. Sleep cycle characteristics in infants. Pediatrics 1969;43:65-70.
Bekedan DJ, Visser GHA, de Vries JJ, Prechtl, HFR. Motor behavior in the growth retarded fetus. Early Hum Dev 1985;12:155-165.

28. van Kranen-Mastenbroek VHJM, Kingma, $\mathrm{H}$, Caberg $\mathrm{H}$, et al. Quality of spontaneous general movements full-term small for gestational age and appropriate for gestational newborn infants. Neuropediatrics 1994;25:145-153.

29. Prechtl HFR, Einspieler C, Cioni G, Bos AF, Ferrari F, Sontheimer D. An early marker for neurological deficits perinatal brain lesions. Lancet 1997:1361-1363. 